\title{
Phosphitispora fastidiosa gen. nov. sp. nov., a new dissimilatory phosphite-oxidizing anaerobic bacterium isolated from anaerobic sewage sludge
}

\author{
Zhuqing Mao ${ }^{1,2}$, Fabian Gräßle1, Jasmin Frey ${ }^{1}$, Paolo Franchini', David Schleheck ${ }^{1,2}$, Nicolai Müller ${ }^{1}$ and \\ Bernhard Schink ${ }^{1,2, *}$
}

\begin{abstract}
A new strictly anaerobic bacterium, strain DYL19', was enriched and isolated with phosphite as the sole electron donor and $\mathrm{CO}_{2}$ as a single carbon source and electron acceptor from anaerobic sewage sludge sampled at a sewage treatment plant in Constance, Germany. It is a Gram-positive, spore-forming, slightly curved, rod-shaped bacterium which oxidizes phosphite to phosphate while reducing $\mathrm{CO}_{2}$ to biomass and small amounts of acetate. Optimal growth is observed at $30^{\circ} \mathrm{C}, \mathrm{pH} 7.2$, with a doubling time of 3 days. Beyond phosphite, no further inorganic or organic electron donor can be used, and no other electron acceptor than $\mathrm{CO}_{2}$ is reduced. Sulphate inhibits growth with phosphite and $\mathrm{CO}_{2}$. The $\mathrm{G}+\mathrm{C}$ content is $45.95 \mathrm{~mol} \%$, and dimethylmenaquinone-7 is the only quinone detectable in the cells. On the basis of 16S rRNA gene sequence analysis and other chemotaxonomic properties, strain DYL19 is described as the type strain of a new genus and species, Phosphitispora fastidiosa gen. nov., sp. nov.
\end{abstract}

Phosphorus is the eleventh most abundant element in Earth's crust and plays a key role in all life forms. The most common phosphorus compound in nature is phosphate, but phosphite, hypophosphite and phosphine also can be detected in small amounts $[1,2]$. In living cells, phosphate esters such as ATP, ADP, AMP, DNA, RNA and phospholipids play key roles in energy metabolism and cell matter synthesis. Due to its importance in living cells and the limited availability of dissolved phosphate in natural environments, phosphate is often the limiting factor for plant growth, e.g. for growth of aquatic plants in freshwater lakes [3]. Phosphate fertilisers help to overcome phosphate limitation in agriculture to secure human food production and to support sustainable development, but they also cause environmental pollution and eutrophication of inland waters. More recently, phosphite fertilisers are being developed and may help to replace phosphate fertilisers because phosphites are more soluble than phosphates, and phosphite is more readily absorbed into plant tissues than phosphate [4]. Phosphites as biostimulants can increase the economics of farms [5] and improve nitrogen fixation efficiency and crop yield, thus reducing leaching and potential damage to the environment.

Geochemical evidence suggests that phosphite was abundant on the primitive Earth [6]. Therefore, the study of microbial phosphite metabolism is of significance to our understanding of the early evolution of life on Earth. Sources of reduced phosphorus compounds include phosphide minerals such as schreibersite $(\mathrm{Fe}, \mathrm{Ni})_{3} \mathrm{P}$, lightning strokes and geothermal fluids. Numerous bacteria can use phosphite as a phosphorus source in the synthesis of cell material, e.g., Pseudomonas stutzeri strain WM88 [7]. Oxidation of reduced phosphorus compounds such as phosphite $\left(\mathrm{HPO}_{3}{ }^{2-}\right)$ to phosphate $\left(\mathrm{HPO}_{4}^{2-}\right)$ releases electrons at an unusually low redox potential $\left(E_{0}{ }^{\prime}=-650 \mathrm{mV}\right)$. Hence, phosphite is a very potent electron source, but so far only very few bacteria can use it in their energy metabolism. Desulfotignum phosphitoxidans strain FIPS-3 was described first to oxidize phosphite as an electron donor in its energy metabolism; it was isolated from marine sediment in Venice, Italy [8, 9]. More recently, a phosphite-oxidizing enrichment culture from a wastewater treatment plant was reported [10]. In the present paper, we describe

Author affiliations: 'Department of Biology, University of Konstanz, Constance, Germany; ${ }^{2}$ Konstanz Research School Chemical Biology, University of Konstanz, Constance, Germany.

*Correspondence: Bernhard Schink, bernhard.schink@uni-konstanz.de

Keywords: Phosphitispora fastidiosa gen. nov., sp. nov; phosphite oxidation; sporulation.

Abbreviations: AAl, average amino acid identity; FAME, fatty acid methyl ester.

The GenBank accession numbers are MZ227813 for the 16 S rRNA gene sequence. The genome was annotated at the Integrated Microbial Genomes and Microbiomes (IMG/M) platform and is available under IMG Taxon ID 2888950683. The Whole Genome Shotgun project has been deposited at DDBJ/ENA/GenBank under the accession JAHHUL000000000. The version described in this paper is version JAHHUL010000000. 
a novel phosphite-oxidizing bacterium, Phosphitispora fastidiosa gen. nov., sp. nov.

Strain DYL19 ${ }^{\mathrm{T}}$ was enriched and isolated from digesting anaerobic sewage sludge obtained from the municipal wastewater treatment plant in Constance, Germany. Enrichment cultures contained $10 \mathrm{mM}$ sodium phosphite as the sole electron source in anoxic, bicarbonate-buffered, sulphidereduced freshwater mineral medium under an oxygen-free mixture of $\mathrm{N}_{2} / \mathrm{CO}_{2}(80 / 20)$ [11]. $2.5 \mathrm{~g} \mathrm{l}^{-1} \mathrm{NaHCO}_{3}, 1 \mathrm{mM}$ $\mathrm{Na}_{2} \mathrm{~S} \cdot 9 \mathrm{H}_{2} \mathrm{O}, 1 \mathrm{ml}$ trace element solution SL-10 [12], $1 \mathrm{ml}$ selenite-tungstate [13] and $1 \mathrm{ml}$ seven-vitamin solution [14] were added from concentrated stock solutions after cooling. The initial $\mathrm{pH}$ of the medium was adjusted to $\mathrm{pH}$ 7.2. Cultivation was performed in $100 \mathrm{ml}$ and 11 glass bottles with butyl rubber stoppers under $\mathrm{N}_{2} / \mathrm{CO}_{2}(80: 20$; v/v) gas atmosphere in the dark at $30^{\circ} \mathrm{C}$. Pure cultures were obtained by repeated agar (1\%) shake dilutions [11] and repeated pasteurization. Purity was checked by phase contrast light microscopy (Axiophot, Zeiss; with internal size calibration) after growth with $10 \mathrm{mM}$ phosphite in the presence and absence of a mix of $10 \mathrm{mM}$ glucose plus $10 \mathrm{mM}$ fumarate and $0.05 \%(\mathrm{w} / \mathrm{v})$ yeast extract. Pure cultures were transferred every 3 weeks and stored in liquid medium at $4{ }^{\circ} \mathrm{C}$. Photographs were taken using the agar slide technique [15]. Gram-staining was performed using a staining kit (Difco Laboratories) according to the manufacturer's instructions, and confirmed by the $\mathrm{KOH}$ test [16]. Spore formation was checked microscopically after growth in the presence of 1 $\mathrm{mM} \mathrm{MnSO}$, and by testing growth after repeated pasteurization at $80^{\circ} \mathrm{C}$ for $20 \mathrm{~min}$.

Utilization of various carbon sources at $10 \mathrm{mM}$ concentration was tested in freshwater medium. Reduction of nitrate $(10 \mathrm{mM})$ and sulphate $(10 \mathrm{mM})$ was checked via nitrite and sulphide formation. Nitrate or nitrite were analysed with commercial test strips (Quantofix, Macherey-Nagel). Sulphide was quantified by the method described by Cline [17]. All tests were conducted independently in duplicates.

Growth was monitored by measuring the optical density at $600 \mathrm{~nm}$ wavelength in a cuvette photometer (Spectrophotometer Jenway 6300) or in a tube photometer (M107, Camspec Analytical Instruments). Phosphite and phosphate were separated by HPLC on a Rezex RHM-Monosaccharide $\mathrm{H}+(8 \%)$ column, 300/7.8 $\mathrm{mm}$ (Phenomenex) as described previously $[18,19]$. Phosphite and phosphate eluted after $9.2 \mathrm{~min}$ and $10.4 \mathrm{~min}$, respectively, with $30 \mathrm{mM}$ sulphuric acid as eluent at $0.6 \mathrm{ml}$ per min flow rate at $40{ }^{\circ} \mathrm{C}$, and were detected by optical diffraction (refractive index detector RID$10 \mathrm{~A}$, Shimadzu). With the same method, acetate eluted after $16.8 \mathrm{~min}$ and sulphate after $7.6 \mathrm{~min}$. Chromatograms were recorded and their analysis performed with Lab Solutions software (Shimadzu).

Hydrogen formation was analysed with a high-sensitivity gas chromatograph Peak Performer 1 (PEAK Laboratories) equipped with a reducing compound photometer, with $\mathrm{N}_{2}$ as carrier gas.
The mol\% G+C content was analysed by HPLC with DNA isolated from $2 \mathrm{~g}$ wet cell biomass $[20,21]$ by the Identification Service of DSMZ (Braunschweig, Germany). Fatty acid methyl esters (FAMEs) were analysed with about $40 \mathrm{mg}$ freeze-dried cells grown with $10 \mathrm{mM}$ phosphite at $30^{\circ} \mathrm{C}$ and harvested in the late stationary phase. The FAME mixtures were separated using the Sherlock Microbial Identification System (MIDI) consisting of an Agilent model $6890 \mathrm{~N}$ gas chromatograph fitted with a $5 \%$ phenyl-methyl silicone capillary column $(0.2 \mathrm{~mm} \times 25 \mathrm{~m})$, a flame ionization detector, an Agilent model 7683A automatic sampler, and an HP computer with the MIDI database (Hewlett-Packard). Peaks were integrated automatically and fatty acid percentages were calculated by the MIS Standard Software (Microbial ID) [22-24] by the Identification Service of the DSMZ (Braunschweig, Germany) who also analysed the respiratory quinones by thin-layer chromatography.

Enrichment cultures with $10 \mathrm{mM}$ phosphite as electron donor and $10 \mathrm{mM}$ sulphate plus $\mathrm{CO}_{2}$ as electron acceptor exhibited turbidity after $4-6$ weeks of incubation at $30{ }^{\circ} \mathrm{C}$. After five transfers, cultures were dominated by a slightly curved, rodshaped, spore-forming bacterium. After repeated pasteurization and dilution in agar-solidified medium, white-yellow lens- to UFO-like shaped colonies were observed in the agar from which pure cultures were obtained. As judged from phase contrast microscopy, these isolates were morphologically identical. Of these, strain DYL19 ${ }^{\mathrm{T}}$ was further characterized.

Cells of strain DYL1 $19^{\mathrm{T}}$ were slightly curved rods, 5-9 $\mu \mathrm{m}$ long and $1 \mu \mathrm{m}$ wide, formed terminally to subterminally located oval spores (Fig. 1), and stained Gram-positive. During growth, the optical density $\left(\mathrm{OD}_{600}\right)$ increased from 0.05 to 0.45 , while phosphite was oxidized completely to phosphate, and $\mathrm{CO}_{2}$ was reduced to biomass and small amounts of acetate (about $0.5 \mathrm{mM}$ acetate from $10 \mathrm{mM}$ phosphite, corresponding to ca. $20 \%$ of the total electrons supplied). No other organic products (fatty acids, lactate, succinate, alcohols) could be detected by HPLC after 60 min analysis under the conditions described above.

Numerous compounds were tested as possible growth substrates. No growth was observed with acetate, acetone, arabinose, 4-amino benzoate, benzoate, betaine, butyrate, choline, crotonate, ethylamine, fumarate, formate, glucose, glutamate, glycine, glycolate, glyphosate, glutarate, hypophosphite, lactate, malate, maleate, methanol, methyl phosphonate, dimethyl phosphonate, 2-oxoglutarate, phenol, proline, 1,2-propanediol, pyruvate, sarcosine, succinate, xylose, yeast extract $(0.1 \% \mathrm{w} / \mathrm{v})$, aniline $(2 \mathrm{mM}), \mathrm{H}_{2}$ or CO (each about $10 \%$ in the headspace) with or without sulphate as electron acceptor. Fumarate, nitrate, sulphate, sulphite, thiosulphate, sulphur and $\mathrm{Fe}(\mathrm{OH})_{3}$ were not reduced with phosphite as electron donor. All substrate tests were run at least twice. Growth with phosphite was partially inhibited by addition of $10 \mathrm{mM}$ sulphate, and no sulphide was formed.

Strain DYL19 ${ }^{\mathrm{T}}$ grew well in freshwater or brackish water (with additional $1 \% \mathrm{w} / \mathrm{v}$ salt [11]) medium and very slowly in marine (with additional 2\% (w/v) salt [11]) medium. It grew optimally 


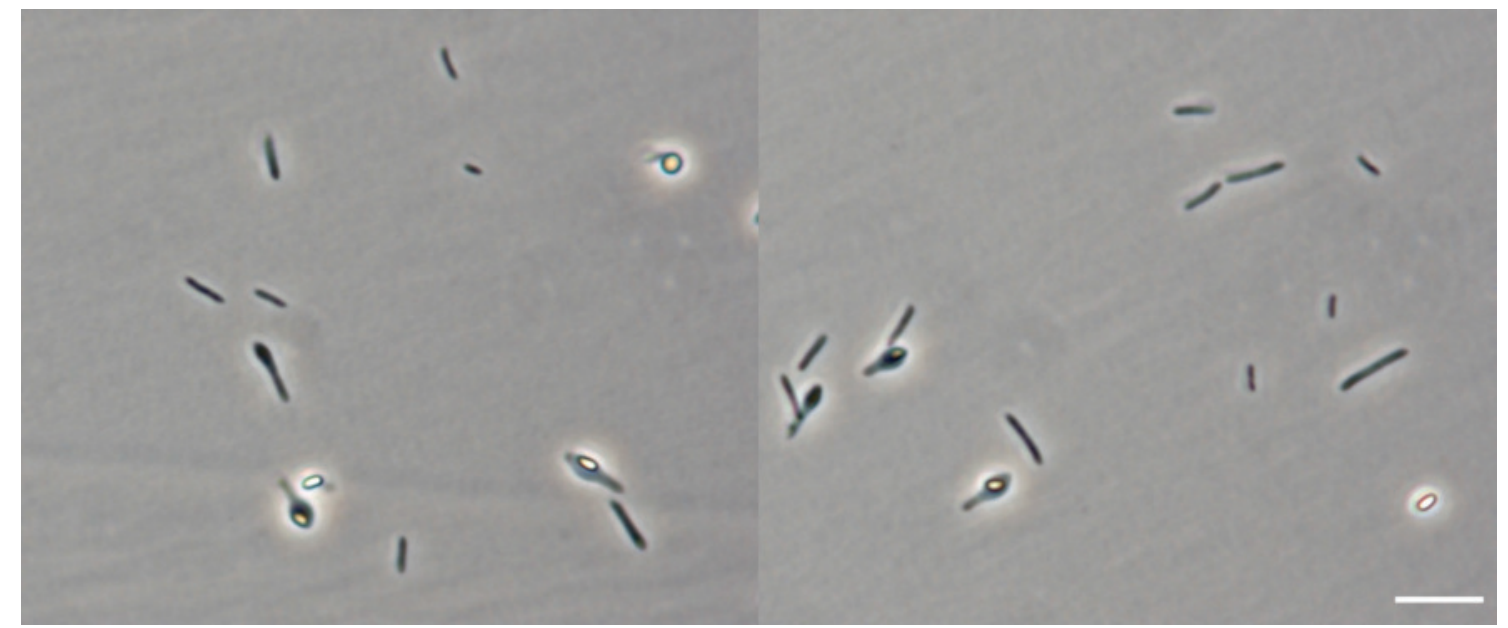

Fig. 1. Phase-contrast microscopy image of cells of strain DYL19', after growth with $10 \mathrm{mM}$ sodium phosphite and carbon dioxide as sole electron acceptor, including sporulated cells and free spores. Bars, $5 \mu \mathrm{m}$.

with phosphite as electron donor and $\mathrm{CO}_{2}$ as electron acceptor at $30^{\circ} \mathrm{C}$ and $\mathrm{pH}$ 7.2. The doubling time was 3 days and the growth yield after complete oxidation of $10 \mathrm{mM}$ phosphite to phosphate was $10.2 \mathrm{~g}$ cell dry mass per mol phosphite.

The DNA G+C content was $45.95 \mathrm{~mol} \%$. The only respiratory quinone found was dimethyl menaquinone-7. Polar lipids were mainly phosphatidylethanolamine, phosphatidylglycerol and diphosphatidylglycerol. The major fatty acids were $\mathrm{C}_{14: 0}, \mathrm{C}_{16: 1} \omega 9 c, \mathrm{C}_{18: 1} \omega 9 c$ and $\mathrm{C}_{18: 1} \omega 11 c$ DMA (Fig. S1, available in the online version of the article).

Genomic DNA was isolated by the JGI-protocol 'Bacterial genomic DNA isolation using CTAB' [19]. Genome sequencing raw data, a total of 6903600 paired-end reads obtained with an Illumina NovaSeq 6000 platform, were provided by Eurofins Genomics Europe Sequencing $\mathrm{GmbH}$ (Constance, Germany). Trimmomatic version 0.39 [25] was used to remove remaining adapters from the reads with default settings, to filter the reads by quality (LEADING:3 TRAILING:3 SLIDINGWINDOW:4:20) and to discard those shorter than $50 \mathrm{bp}$. The resulting reads were de novo assembled with SPAdes version 3.14.1 [26] using the 'isolate' option and kmer sizes of 21,33, 55 and 77. The assembly procedure generated 255 scaffolds. Bowtie2 version 2.4.1 [27] and Samtools version 1.9 [28] were used to align the trimmed reads back to the assembled scaffolds (default settings) and to calculate the average fold, respectively. Finally, the scaffolds were sorted in descending order according to their length and annotated by Joint Genome Institute Integrated Microbial Genomes and Microbiomes Genomes OnLine Database (GOLD) [29]. The genome annotation is publicly available in IMG under GOLD Analysis Project ID Ga0451573 (IMG Taxon ID 2888950683) and in GenBank under the accession JAHHUL000000000.

For amplifying the $16 \mathrm{~S}$ rRNA gene by PCR, a crude preparation of genomic DNA was obtained by centrifugation of
$10 \mathrm{ml}$ culture of strain DYL19 ${ }^{\mathrm{T}}$ at $10000 \mathrm{~g}$ for $10 \mathrm{~min}$. The supernatant was discarded and the cell pellet was washed once by suspending in $1.5 \mathrm{ml}$ PCR quality $\mathrm{H}_{2} \mathrm{O}$ (MP Biomedicals) followed by repeated centrifugation. The cell pellet was suspended in $50 \mu \mathrm{PCR} \mathrm{H}_{2} \mathrm{O}$ and incubated at $99^{\circ} \mathrm{C}$ for 10 min. After chilling on ice, this mixture was centrifuged again and the DNA-containing supernatant was stored at $-20^{\circ} \mathrm{C}$ until further use. The $16 \mathrm{~S}$ rRNA gene was amplified by PCR using the primers $8 \mathrm{~F}$ (5'-AGAGTTTGATCCTGGCTCAG-3') [30] or 533F (5'-GTGCCAGCAGCCGCGGTAA-3') [31] and 1492R (5'-TACGGYTACCTTGTTACGACTT-3') [31] and a ready-to-use reaction mix (Bioline/Meridian Bioscience Mango Mix, BioCat) according to the manufacturer's instructions. The reaction was performed with an initial denaturation at $96^{\circ} \mathrm{C}$ for 2 min followed by 32 cycles of $94^{\circ} \mathrm{C}$ for 40 $\mathrm{s}, 54{ }^{\circ} \mathrm{C}$ for $40 \mathrm{~s}, 72{ }^{\circ} \mathrm{C}$ for $60 \mathrm{~s}$, and a final extension at $72{ }^{\circ} \mathrm{C}$ for $5 \mathrm{~min}$. The amplified 16S rRNA gene fragment of approximately $1.4 \mathrm{~kb}$ was purified using a DNA purification kit (DNA clean and concentrator, Zymo Research) and sequenced at Eurofins Genomics Europe Sequencing GmbH. The 16S rRNA gene sequence was trimmed and assembled with the genious software (Biomatters), and the resulting assembled DNA-sequence (1461 bp) was analysed with a BLASTNsearch to identify close phylogenetic relatives [32] (http:// blast.ncbi.nlm.nih.gov/Blast.cgi). This search revealed that strain DYL19 ${ }^{\mathrm{T}}$ is a member of the family Peptococcaceae. The species most similar to strain DYL19 ${ }^{\mathrm{T}}$ were the Gram-positive bacteria Thermincola ferriacetica strain Z-0001 [33] with 91.7\% sequence identity and Thermoanaerosceptrum fracticalcis DRI-13 [34], which both are phylogenetically far remote from the Gram-negative Desulfotignum phosphitoxidans. The assembled 16S rRNA gene sequence was also used for a BLASTN-search against the genome sequence of strain DYL19 ${ }^{\mathrm{T}}$ using BLAST integrated in IMG to reveal possible mutations that might have occurred during PCR amplification using a non-proofreading DNA polymerase (https://img.jgi.doe.gov). 


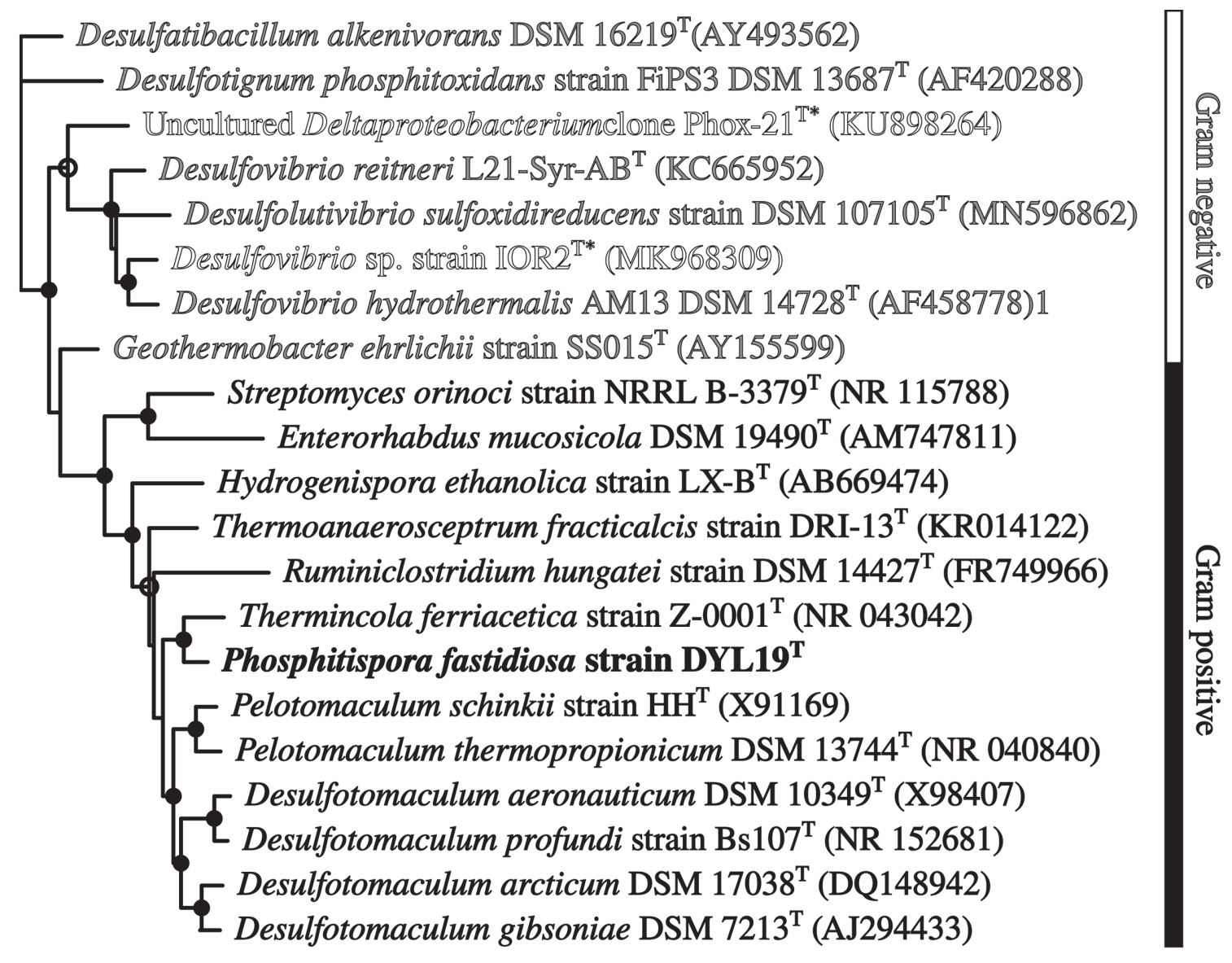

Fig. 2. Phylogenetic tree based on the $16 \mathrm{~S}$ rRNA gene sequence comparison. Empty circles indicate a bootstrap support of $>70 \%$, full circles $>90 \%$ derived form 1000 samples. Scale bar indicates one nucleotide substitution per site. Gram-positive strains are marked in bold, Gram-negative strains are marked in grey and uncultured clones in white. The alignment was calculated using the sINA Aligner and the tree was created using IQ-Tree. The tree was visualized using iTOL version 6.

This $16 \mathrm{~S}$ rRNA gene sequence exhibited $100 \%$ identity with the gene with the locus tag Ga0451573_046_206_1739 and carries the annotation $16 \mathrm{~S}$ rRNA. We therefore considered this sequence as the 16S rRNA gene, which thereafter was used to reconstruct a phylogenetic tree.

The 16S rRNA gene sequence of DYL19 ${ }^{\mathrm{T}}$ was also analysed using the identification service of EzBioCloud. An alignment with related strains was calculated using the sinA Aligner online tool (www.arb-silva.de/aligner) removing bases remaining unaligned at the ends. The alignment of marker genes from the genome sequences was calculated using the Genome Taxonomy Database toolkit (gtdb-tk) [35]. Both alignments were used to calculate trees with IQ-Tree [36]. The trees were then visualized in the online tool iTOL version 6 (https://itol.embl.de/) [37] (Fig. 2). Phylogenetic analysis of the almost complete $16 \mathrm{~S}$ rRNA gene identified strain DYL $19^{\mathrm{T}}$ as a member of the family Peptococcaceae within the order Clostridiales.
Illumina sequencing and assembly of the genome of strain DYL19 ${ }^{\mathrm{T}}$ yielded a total of $4094493 \mathrm{bp}$, with a DNA-coding number of basepairs of 3612790 bp on 255 scaffolds with $45.95 \mathrm{~mol} \% \mathrm{G}+\mathrm{C}$ content. The genome contains 15 genes annotated as $16 \mathrm{~S}$ rRNA, of which 14 are most likely misannotated 250 to $350 \mathrm{bp}$ fragments, while only one of these genes (Ga0451573_046_206_1739) has a size of 1534 bp as expected for a complete 16S rRNA gene. The genome harbours 3056 protein-coding genes with function prediction and of these 924 are connected to KEGG pathways and 760 are connected to MetaCyc pathways. Of the latter, 171 are predicted to be involved in energy metabolism, among them genes for oxidative phosphorylation (NADH: quinone oxidoreductase subunits $\mathrm{A}$ to $\mathrm{N}$ ) and various genes whose proteins are associated with $\mathrm{C} 1$-metabolism and $\mathrm{CO}_{2}$ fixation via the Wood-Ljungdahl pathway (carbon monoxide dehydrogenase, formate dehydrogenase, [methyl-Co(III) methanolspecific corrinoid protein]:coenzyme $\mathrm{M}$ methyltransferase, methylamine-corrinoid protein Co-methyltransferase and 


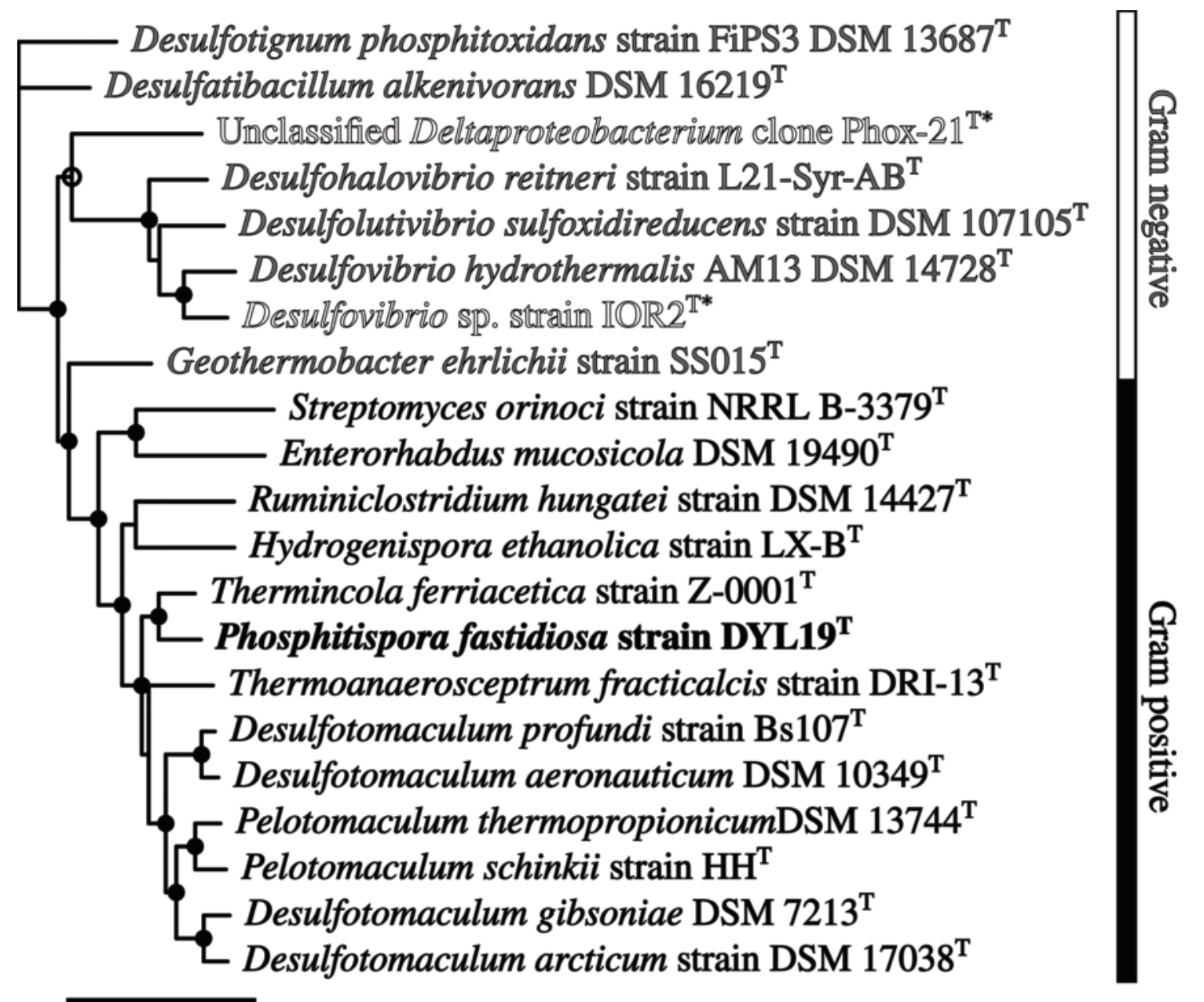

Fig. 3. Phylogenetic tree based on the genome sequence comparison. Empty circles indicate a bootstrap support of $>70 \%$, full circles $>90 \%$ derived form 1000 samples. Scale bar indicates one nucleotide substitution per site. Gram-positive strains are marked in black, Gram-negative strains are marked in grey and uncultured clones in white. The alignment was calculated using gtdb-tk and the tree was created using IQ-Tree. The tree was visualized using iTOL version 6.

trimethylamine-corrinoid protein Co-methyltransferase). It is therefore surprising that strain DYL19 ${ }^{\mathrm{T}}$ apparently has no other growth mode available than anaerobic growth with phosphite as electron donor and $\mathrm{CO}_{2}$ as electron acceptor.

The alignment of the genome tree was calculated using gtdb-tk, and the alignment of the 16S rRNA gene tree was calculated using the sinA Aligner. The genome tree is shown in Fig. 3. Average amino acid identity (AAI) values of strain DYL1 $19^{\mathrm{T}}$ with all strains used in the trees were pairwise calculated using the software toolkit CompareM and are listed in Table 1.

We propose that DYL19 ${ }^{\mathrm{T}}$ represents a novel bacterial genus and species within the family Peptococcaceae. For the closest described relative Thermincola ferriacetica, a 16S rRNA gene sequence identity of $91.7 \%$ was calculated. As the currently recommended thresholds for the classification of new species and genera by $16 \mathrm{~S}$ rRNA gene similarity are $98.7 \%$ [38] and $94.5 \%$ [39] respectively, a classification as a novel genus is indicated. Analysis of AAI of the genome of strain DYL19 ${ }^{\mathrm{T}}$ with other closely related strains confirms this classification as a new genus as the AAI threshold for the same genus is $65 \%$ [40] and the highest values calculated for the reference type strain observed in this study is $62.8 \%$.

Strain DYL19 ${ }^{\mathrm{T}}$ differs from its closest relatives, Thermincola ferriacetica and Thermoanaerosceptrum fracticalcis, by being mesophilic. Moreover, neither one of these two species contains genes in its published genome that are indicative of dissimilatory oxidation of phosphite, which is the only substrate that our strain DYL19 $19^{\mathrm{T}}$ can use. Based on these results, we suggest assign strain DYL19 ${ }^{\mathrm{T}}$ to a novel genus and species, Phosphitispora fastidiosa.

Desulfotignum phosphitoxidans, so far the only described pure culture of a bacterium growing by dissimilatory phosphite oxidation, was isolated from marine sediment $[8,9]$. The new dissimilatory phosphite oxidizer we present here, strain 
Table 1. Pairwise amino acid identity (\%) values of genomes used in this study compared to the genome of strain DYL19 ${ }^{\top}$

Values were calculated using the software toolkit CompareM.

\begin{tabular}{|c|c|c|}
\hline Genome & $\begin{array}{l}\text { Accession } \\
\text { no. }\end{array}$ & $\begin{array}{l}\text { \% AAI with } \\
\text { DYL19 }^{\mathrm{T}}\end{array}$ \\
\hline Enterorhabdus mucosicola DSM $19490^{\mathrm{T}}$ & ASM42262v & 46.7 \\
\hline $\begin{array}{l}\text { Desulfatibacillum alkenivorans DSM } \\
16219^{\mathrm{T}}\end{array}$ & & 46.6 \\
\hline Desulfovibrio sp. IOR2 ${ }^{\mathrm{T}}$ & ASM800123 & 45.8 \\
\hline Desulfotomaculum profundi strain Bs $107^{\mathrm{T}}$ & ASM260785 & 55.9 \\
\hline $\begin{array}{l}\text { Desulfotignum phosphitoxidans DSM } \\
13687^{\mathrm{T}}\end{array}$ & & 45.9 \\
\hline Thermincola ferriacetica strain Z- $0001^{\mathrm{T}}$ & ASM126341 & 62.9 \\
\hline Geothermobacter ehrlichii strain SS015 ${ }^{\mathrm{T}}$ & ASM812461 & 48.4 \\
\hline Pelotomaculum schinkii strain $\mathrm{HH}^{\mathrm{T}}$ & ASM436920 & 55.6 \\
\hline Desulfotomaculum arcticum DSM $17038^{\mathrm{T}}$ & & 55.0 \\
\hline Hydrogenispora ethanolica strain LX-B ${ }^{\mathrm{T}}$ & ASM434068 & 50.8 \\
\hline $\begin{array}{l}\text { Desulfotomaculum aeronauticum DSM } \\
10349^{\mathrm{T}}\end{array}$ & & 55.3 \\
\hline Streptomyces orinoci strain NRRL B- $3379^{\mathrm{T}}$ & ASM312129 & 45.0 \\
\hline $\begin{array}{l}\text { Desulfolutivibrio sulfoxidireducens DSM } \\
107105^{\mathrm{T}}\end{array}$ & ASM133764 & 45.9 \\
\hline $\begin{array}{l}\text { Unclassified Deltaproteobacterium clone } \\
\text { Phox- } 21^{\mathrm{T}}\end{array}$ & & 46.8 \\
\hline Desulfotomaculum gibsoniae DSM $7213^{\mathrm{T}}$ & ASM23371v & 55.3 \\
\hline $\begin{array}{l}\text { Desulfovibrio hydrothermalis AM13 DSM } \\
14728^{\mathrm{T}}\end{array}$ & ASM42524v & 45.7 \\
\hline $\begin{array}{l}\text { Desulfohalovibrio reitneri strain L21-Syr- } \\
\mathrm{AB}^{\mathrm{T}}\end{array}$ & ASM71129v & 45.7 \\
\hline $\begin{array}{l}\text { Thermoanaerosceptrum fracticalcis strain } \\
\text { DRI- } 13^{\mathrm{T}}\end{array}$ & ASM74602v & 54.3 \\
\hline $\begin{array}{l}\text { Pelotomaculum thermopropionicum DSM } \\
13744^{\mathrm{T}}\end{array}$ & ASM1056v1 & 56.4 \\
\hline Ruminiclostridium hungatei DSM $14427^{\mathrm{T}}$ & ASM205158 & 50.2 \\
\hline
\end{tabular}

DYL19 ${ }^{\mathrm{T}}$, is a Gram-positive spore-former and was isolated from a freshwater sewage treatment plant. Comparison of the 16S rRNA gene sequences (Fig. 2) indicates that strain DYL19 ${ }^{\mathrm{T}}$ has very little in common with the formerly described Gramnegative $D$. phosphitoxidans or with the phosphite-oxidizing enrichment culture Phox-21 described more recently [10]. Different from the metabolically versatile $D$. phosphitoxidans, strain DYL19 ${ }^{\mathrm{T}}$ has no sulphate reduction genes and oxidizes only phosphite to phosphate while reducing $\mathrm{CO}_{2}$ to small amounts of acetate plus cell material. Obviously, the capacity for dissimilatory phosphite oxidation is found in different branches of the phylogenetic tree of bacteria, even though we do not yet understand the biochemical concept of this unusual type of energy metabolism.

\section{DESCRIPTION OF PHOSPHITISPORA GEN. NOV.}

Phosphitispora (Phos.phi.ti.spo'ra. N.L. neut. n. phosphitum, phosphite; Gr. fem. n. spora, seed or spore; N.L. fem. n. Phosphitispora, a phosphite-oxidizing spore-former).

Cells are Gram-positive, rod-shaped, strictly anaerobic and form thermoresistant spores. Growth is mesophilic; grows optimally in freshwater medium. A member of the family Peptococcaceae in the order Eubacteriales. The type species is Phosphitispora fastidiosa sp. nov.

\section{DESCRIPTION OF PHOSPHITISPORA FASTIDIOSA SP. NOV.}

Phosphitispora fastidiosa (fas.ti.di.o'sa. L. fem. adj. fastidiosa, fastidious, picky, referring to its very small substrate range).

Gram-positive, rod-shaped bacterium forming terminal to subterminal oval spores. Oxidizes phosphite to phosphate by reducing $\mathrm{CO}_{2}$ to acetate and cell mass. No other organic or inorganic electron donors used; no reduction of nitrate, nitrite, sulphate, sulphite, thiosulphate, sulphur or iron (III) hydroxide. Growth occurs at $20-35^{\circ} \mathrm{C}$ and $\mathrm{pH}$ 7.0-8.0. Optimal growth occurs in freshwater and brackish water media with 0.1-1.0 \% (w/v) NaCl, at $30^{\circ} \mathrm{C}$, pH 7.2 and $0.1 \%$ (w/v) NaCl. Dimethylmenaquinone-7 is the only respiratory quinone. The predominant polar lipids are phosphatidylethanolamine, phosphatidylglycerol and diphosphatidylglycerol. Major fatty acids are $\mathrm{C}_{14: 0^{\circ}}, \mathrm{C}_{16: 1} \omega 9 c$, $\mathrm{C}_{18: 1} \omega 9 c$ and $\mathrm{C}_{18: 1} \omega 11 c$ DMA.

The type strain is DYL19 ${ }^{\mathrm{T}}\left(\right.$ KCTC $\left.25291^{\mathrm{T}}=\mathrm{GDMCC} 1.2680^{\mathrm{T}}\right)$, which was isolated from anaerobic sewage sludge of a wastewater treatment plant in Constance, Germany. The DNA G+C content of the type strain is $45.95 \mathrm{~mol} \%$.

\section{Funding information}

This study was supported through a scholarship by the Deutscher Akademischer Austauschdienst (DAAD) Bonn, Germany, to Zhuqing Mao, and by research funds of the University of Konstanz.

\section{Acknowledgements}

We thank the Deutscher Akademischer Austauschdienst (DAAD) who provided a scholarship for Z.M. within the programme of the Konstanz Research School Chemical Biology. The Joint Genome Institute is acknowledged for the annotation of the genome sequence. Work conducted by the U.S. Department of Energy Joint Genome Institute, a DOE Office of Science User Facility, is supported by the Office of Science of the U.S. Department of Energy under Contract No. DE-AC0205CH11231. Z.M. is grateful for support from Duan Yuanling, from Sylke Wiechmann for preparation of the genomic DNA sample, and from Julia Schmidt for help with preparation of culture media.

\section{Conflicts of interest}

The authors declare that there are no conflicts of interest.

\section{References}

1. Pasek MA, Sampson JM, Atlas Z. Redox chemistry in the phosphorus biogeochemical cycle. Proc Natl Acad Sci USA 2014;111:15468-15473.

2. Figueroa IA, Barnum TP, Somasekhar PY, Carlström Cl, Engelbrektson AL, et al. Metagenomics-guided analysis of microbial chemolithoautotrophic phosphite oxidation yields evidence 
of a seventh natural $\mathrm{CO}_{2}$ fixation pathway. Proc Natl Acad Sci USA 2018;115:E92-E101.

3. Schink B. Biological cycling of phosphorus. In: Sigel A, Sigel $\mathrm{H}$ and Sigel RKO (eds). Ions in Biological Systems. New York, USA: Marcel Dekker Inc; 2005. pp. 131-151.

4. Lovatt CJ, Mikkelsen RL. Phosphite fertilizers: What are they? Can you use them? What can they do. Better crops 2016;4:611-613.

5. Rossall S, Qing C, Paneri M, Bennett M, Swarup R. A 'growing' role for phosphites in promoting plant growth and development. Acta Hortic 2016:61-68.

6. Pasek MA, Harnmeijer JP, Buick R, Gull M, Atlas Z. Evidence for reactive reduced phosphorus species in the early Archean ocean. Proc Natl Acad Sci U S A 2013;110:10089-10094.

7. Metcalf WW, Wolfe RS. Molecular genetic analysis of phosphite and hypophosphite oxidation by Pseudomonas stutzeri WM88. J Bacteriol 1998;180:5547-5558.

8. Schink B, Friedrich MW. Phosphite oxidation by sulphate reduction. Nature 2000:406:37.

9. Schink B, Thiemann V, Laue H. Friedrich MW. Desulfotignum phosphitoxidans sp. nov., a new marine sulfate reducer that oxidizes phosphite to phosphate. Arch Microbiol 2002;177:381-391.

10. Figueroa IA, Coates JD. Microbial phosphite oxidation and its potential role in the global phosphorus and carbon cycles. Adv Appl Microbiol 2017;98:93-117.

11. Widdel F, Bak F. Gram negative mesophilic sulfate reducing bacteria. In: Balows H, Trüper HG, Dworkin M, Harder W and Schleifer KH (eds). The Prokaryotes, Vol. IV. New York: Springer: 1992. pp. 3352-3378

12. Widdel F, Kohring GW, Mayer F. Studies on dissimilatory sulfatereducing bacteria that decompose fatty acids. Arch Microbiol 1983;134:286-294

13. Tschech A, Pfennig N. Growth yield increase linked to caffeate reduction in Acetobacterium woodii. Arch Microbiol 1984:137:163-167.

14. Pfennig N. Rhodocyclus purpureus gen. nov. and sp. nov., a ringshaped, vitamin b12-requiring member of the family Rhodospirillaceae. Int J Syst Bacteriol 1978;28:283-288.

15. Pfennig N, Wagener S. An improved method of preparing wet mounts for photomicrographs of microorganisms. J Microbio Methods 1986:4:303-306.

16. Gregersen T. Rapid method for distinction of Gram-negative from Gram-positive bacteria. Eur J Appl Microbiol Biotechnol 1978:5:123-127.

17. Cline JD. Spectrophotometric determination of hydrogen sulfide in natural waters1. Limnol Oceanogr 1969;14:454-458.

18. Müller N, Scherag FD, Pester M, Schink B. Bacillus stamsii sp. nov., a facultatively anaerobic sugar degrader that is numerically dominant in freshwater lake sediment. Syst Appl Microbiol 2015:38:379-389

19. Patil Y, Junghare M, Müller N. Fermentation of glycerol by Anaerobium acetethylicum and its potential use in biofuel production. Microb Biotechnol 2017;10:203-217.

20. Marmur J. A procedure for the isolation of deoxyribonucleic acid from micro-organisms. J Mol Biol 1961;3:208-IN1.

21. Mesbah M, Premachandran U, Whitman WB. Precise measurement of the $\mathrm{G}+\mathrm{C}$ content of deoxyribonucleic acid by high-performance liquid chromatography. Int J Syst Bacteriol 1989:39:159-167.
22. Kämpfer P, Kroppenstedt RM. Numerical analysis of fatty acid patterns of coryneform bacteria and related taxa. Can J Microbiol 1996:42:989-1005

23. Kuykendall LD, Roy MA, O'neill JJ, Devine TE. Fatty acids, antibiotic resistance, and deoxyribonucleic acid homology groups of Bradyrhizobium japonicum. Int J Syst Bacteriol 1988;38:358-361.

24. Miller LT. Single derivatization method for routine analysis of bacterial whole-cell fatty acid methyl esters, including hydroxy acids. J Clin Microbiol 1982;16:584-586.

25. Bolger AM, Lohse M, Usadel B. Trimmomatic: a flexible trimmer for Illumina sequence data. Bioinformatics 2014;30:2114-2120.

26. Nurk S, Bankevich A, Antipov D, Gurevich A, Korobeynikov A, et al. Assembling genomes and mini-metagenomes from highly chimeric reads. In: Deng M, Jiang R, Sun F and Zhang X (eds). Research in Computational Molecular Biology. RECOMB 2013. Lecture Notes in Computer Science, vol. 7821. Berlin, Heidelberg: Springer; 2013

27. Langmead B, Salzberg SL. Fast gapped-read alignment with Bowtie 2. Nat Methods 2012;9:357-359.

28. Danecek P, Bonfield JK, Liddle J, Marshall J, Ohan V, et al. Twelve years of SAMtools and BCFtools. GigaScience 2021;10:giab008.

29. Mukherjee S, Stamatis D, Bertsch J, Ovchinnikova G, Sundaramurthi JC et al. Genomes OnLine Database (GOLD) v.8: overview and updates. Nucleic Acids Res 2021;49:D723-D733.

30. Turner S, Pryer KM, Miao VPW, Palmer JD. Investigating deep phylogenetic relationships among cyanobacteria and plastids by small subunit rRNA sequence analysis. J Eukaryotic Microbiology 1999:46:327-338.

31. Weisburg WG, Barns SM, Pelletier DA, Lane DJ. 16S ribosomal DNA amplification for phylogenetic study. J Bacteriol 1991;173:697-703.

32. Altschul SF, Gish W, Miller W, Myers EW, Lipman DJ. Basic Local Alignment Search Tool. J Mol Biol 1990;215:403-410.

33. Zavarzina DG, Sokolova TG, Tourova TP, Chernyh NA, Kostrikina NA, et al. Thermincola ferriacetica sp. nov., a new anaerobic, thermophilic, facultatively chemolithoautotrophic bacterium capable of dissimilatory Fe(III) reduction. Extremophiles 2007;11:1-7.

34. Hamilton-Brehm SD, Stewart LE, Zavarin M, Caldwell M, Lawson PA, et al. Thermoanaerosceptrum fracticalcis gen. nov. sp. nov., a novel fumarate-fermenting microorganism from a deep fractured carbonate aquifer of the US Great Basin. Front Microbiol 2019;10:2224

35. Chaumeil P-A, Mussig AJ, Hugenholtz P, Parks DH, Hancock J. GTDB-Tk: a toolkit to classify genomes with the Genome Taxonomy Database. Bioinformatics 2019;36:1925-1927.

36. Nguyen L-T, Schmidt HA, von Haeseler A, Minh BQ. IQ-TREE: a fast and effective stochastic algorithm for estimating maximumlikelihood phylogenies. Mol Biol Evol 2015;32:268-274.

37. Letunic I, Bork P. Interactive Tree Of Life (iTOL) v5: an online tool for phylogenetic tree display and annotation. Nucleic Acids Res 2021;49:W293-W296.

38. Stamatakis A, Hoover P, Rougemont J. A rapid bootstrap algorithm for the RAxML web servers. Syst Biol 2008;57:758-771.

39. Yarza P, Yilmaz P, Pruesse E, Glöckner FO, Ludwig W, et al. Uniting the classification of cultured and uncultured bacteria and archaea using $16 \mathrm{~S}$ rRNA gene sequences. Nat Rev Microbiol 2014;12:635-645.

40. Konstantinidis KT, Rosselló-Móra R, Amann R. Uncultivated microbes in need of their own taxonomy. ISME J 2017;11:2399-2406. 